\title{
Uma janela de oportunidades para a sociologia da ciência
}

Fernanda SOBRAL, Maria Lúcia MACIEL e Michelangelo TRIGUEIRO (orgs.). A alavanca de Arquimedes: ciência e tecnologia na virada do século. Brasília, Paralelo 15, 1997. 174 páginas.

\section{Elizabeth Balbachevsky}

$\mathrm{Na}$ virada do século, as questões relativas ao desenvolvimento científico e tecnológico tenderam a ganhar um destaque inusitado tanto nos meios de comunicação como junto a numerosas áreas da produção acadêmica em todo o mundo. Sua importância decorre do papel estratégico que o sistema de produção de conhecimento passou a desempenhar na sociedade pósindustrial. No Brasil, esse debate tem se ressentido da ausência da perspectiva das ciências sociais. Poucos são os circuitos onde a Sociologia ou a Ciência Política se fazem presentes nessa discussão. Por esse motivo, o primeiro mérito do livro $A$ alavanca de Arquimedes, organizado pelos professores Fernanda Sobral, Maria Lúcia Maciel e Michelangelo Trigueiro, é justamente o de abordar esse tema sob as óticas da Sociologia e da Ciência Política.

Outro mérito inegável do livro decorre de ele ser produto de uma atividade institucional consolidada. $O$ Departamento de Sociologia da Universidade de Brasília acumula trabalhos e reflexões na área da sociologia da ciência que datam de mais de 15 anos. O livro em questão reflete a institucionalização dessa temática no âmbito do
Departamento. Um resultado que contraria a tradicional fragilidade institucional das linhas de pesquisa nas ciências sociais no Brasil. Os artigos do livro são assinados por professores e estudantes do Programa de Doutorado desse Departamento e os temas abordados cobrem um extenso espectro, que vai desde a análise das mudanças mais recentes nas políticas de C\&T no Brasil até a reflexão teórica acerca da contribuição e dos impasses do construtivismo na sociologia da ciência.

Finalmente, um aspecto que também deve ser ressaltado é a maturidade com que os artigos desse livro documentam, discutem e analisam as alterações que se verificam nas políticas e nas práticas da ciência contemporânea. Os trabalhos que constituem a coletânea, se não deixam de ser críticos, estão longe da postura denunciatória ingênua que muitas vezes se observa na discussão das conseqüências da globalização. E a área em questão é uma das mais afetadas por esses processos.

Em artigo publicado em 1995, George Ferné, da OECD, resume com precisão as principais forças que operam na 
redefinição do papel da ciência e da tecnologia na sociedade pós-industrial contemporânea.

Em primeiro lugar, temos a centralidade da dimensão tecnológica em todos os processos sociais e econômicos contemporâneos, que decorre do aumento da eficiência social na mobilização dos recursos de pesquisa e desenvolvimento e, mais especificamente, da crescente capacidade das sociedades avançadas em explorar as oportunidades criadas pelo novo conhecimento.

Em segundo lugar, temos a sobreposição de problemas ambientais gerados pelo progresso econômico e social passado, que se configuram como um conjunto de questões que necessitam ser entendidas e equacionadas em escala global.

Esses processos impuseram uma drástica redefinição da agenda das políticas de C\&T em todos os países do mundo. Fundamentalmente, essas mudanças estão relacionadas a um longo processo que levou à progressiva substituição da questão da defesa como pólo orientador dos investimentos em C\&'T pela questão da competitividade econômica. Já no início dos anos 80 era possível perceber uma crescente convergência entre as políticas de $C \& T$ e as políticas industriais em um grande número de países do Ocidente, pressionados pela competição das indústrias dos países do Sudeste Asiático. O final da Guerra Fria imprimiu uma nova aceleração nesse processo. Um elemento decisivo no novo cenário é o reconhecimento de que, para a competitividade de um país, tão ou mais importante do que a capacidade de produqir novos conhecimentos é a habilidade de identificar,organizar e explorar o conhecimento, venha ele de onde vier.

As conseqüências da nova realidade desdobram-se em múltiplas facetas. Antes de mais nada, pode-se observar uma redefinição dos atores envolvidos na negociação das políticas de C\&T, com a mobilização e representação de um novo ator: os setores empresariais, interessados na integração das questões de C\&T num conjunto maior de políticas orientadas para dar sustentação aos processos de inovação tecnológica. A preocupação com a incorporação da ótica do "consumidor" no processo de formulação das políticas de C\&T é uma mudança radical em relação à situação prevalecente nos anos 60 e 70, caracterizada pela perspectiva do "science push" e o predomínio do paradigma linear de desenvolvimento científico e tecnológico. Paradigma esse que foi genialmente resumido por Vannevar Bush em seu famoso relatório Science, the endless frontier, de 1945. No livro que estamos analisando, algumas dessas questões foram abordadas por Fernando Antônio F. de Barros, no artigo "O planejamento do desenvolvimento científico e tecnológico no contexto neoliberal contemporâneo".

A discussão das políticas de C\&T dentro das balizas colocadas pela questão da inovação tecnológica situa a firma, e não mais o governo, no centro do debate e demanda do governo políticas mais abrangentes, que vão além do financiamento da empreitada científica. Todo o debate que se trava, em vários países, em torno das reformas no ensino superior, nos centros de pesquisa governamentais e na atividade acadêmica em geral tem relação com essa mudança de enfoque. No livro, o artigo de Maria Lúcia Maciel, "Inovação e conhecimento", aborda a questão da inovação tecnológica e traça um instigante paralelo entre a experiência italiana e as possibilidades abertas para o Brasil. Sua análise do caso italiano é surpreendente, já que chama a atenção para a emergência de um robusto sistema de inovação num contexto de relativa ausência de políticas governamentais claramente dirigidas à questão.

Uma outra área onde podemos perceber mudanças é o debate acerca dos mecanismos de indução da produção científica e de seu financiamento. Dentro dessa temática, ganham destaque as questões relativas à orientação da atividade científica para as áreas consideradas estratégicas para a competitividade, o aumento da cooperação entre a academia e o meio empresarial, com o desenvolvimento de projetos cooperativos, o subsídio de pesquisas em tecnologias ditas pré-competivas etc. Alguns desses temas, tendo como referência o Brasil, são abordados por Ana Maria Fernandes no artigo" Possibilidades de desenvolvimento científico e tecnológico no Brasil". Nesse 
artigo, a autora analisa algumas séries históricas de indicadores de C\&T para o Brasil, comparando-as com informações de outros países, e conclui pelo relativo despreparo de nosso sistema de C\&T para os desafios colocados para a economia brasileira. Por outro lado, como salienta a autora, embora não seja possível caracterizar uma inércia institucional nas políticas de suporte à $\mathrm{C} \& \mathrm{~T}$, o ritmo da mudança é lento e poderia ser acelerado. A baixa participação de dois atores cruciais, os do campo econômico e os do empresarial, na definição dessas mudanças aumenta a incerteza dos resultados.

$\mathrm{Na}$ área de formação de recursos humanos, é possível acompanhar uma guinada substancial no conteúdo das políticas em quase todos os países. Em 1996, por exemplo, a National Academy of Science, dos EUA, publicou um relatório revisando a pós-graduação no país. Para um leitor incauto, é surpreendente verificar que esse documento centraliza toda a discussão da pós-graduação em torno da necessidade de incorporar uma perspectiva mais abrangente para a formação da próxima geração de Ph.Ds., preparando-a para um leque mais amplo de alternativas profissionais, inclusive, expressamente, o trabalho em ambientes empresariais. Decididamente, a formação de pesquisadores não é mais uma razão de ser suficiente para justificar o investimento norte-americano na pósgraduação. No artigo "Para onde vai a pós-graduação brasileira?", de Fernanda Sobral, é possível acompanhar a evolução desse debate no Brasil. Sobral realiza uma recuperação histórica das políticas de pós-graduação mediante a análise da evolução dos temas e políticas propostos nos Planos Nacionais de Pós-Graduação. Estes planos, como nos alerta a autora, não são meros exercícios de retórica, já que, fugindo à tradição, a pós-graduação no Brasil foi resultante da consolidação de uma política definida e que se manteve razoavelmente estável ao longo dos anos.

Se esse é o cenário prevalecente no âmbito das políticas de $C \& T$, as alterações que se verificam no interior do campo científico não são menos radicais. Em 1994, Gibbons, Limoge, Nowotny, Schwartzman, Scott e Trow lançaram o livro The new production of knowledge, que sistematiza algumas dessas mudanças: o predomínio de enfoques transdisciplinares no plano cognitivo; a diversificação dos atores e interesses envolvidos no processo da pesquisa; a aproximação entre os contextos de produção e aplicação do conhecimento; a heterogeneidade maior de sítios para o desenvolvimento da pesquisa, caracterizados por novas formas de articulação entre organizações de naturezas distintas; o desenvolvimento de novos critérios para a avaliação da qualidade dos resultados da pesquisa e; a estrutura mais fluida e dinâmica das equipes de pesquisa, em que os componentes hierárquicos são substituídos por processos ampliados de participação na produção e distribuição do conhecimento. No livro que estamos analisando, o artigo de Michelangelo Trigueiro, "O que foi feito de Khun? O construtivismo na sociologia da ciência", oferece um resumo bastante agudo dos resultados desses estudos para o público brasileiro, além de avançar uma estimulante discussão acerca das implicações dessa nova realidade para a perspectiva construtivista na sociologia da ciência. O trabalho, embora marcadamente teórico, ecoa os resultados preliminares da pesquisa desenvolvida por Trigueiro acerca das novas biotecnologias. A qualidade do seu artigo levanta boas expectativas com relação aos resultados futuros da pesquisa.

O artigo assinado por Maria Amália de Gusmão, "O pesquisador e a escolha do objeto de pesquisa", concentra a análise em torno de uma questão que vem recebendo atenção crescente na literatura internacional. Num mundo dominado pela perspectiva dos usos do conhecimento, questões relativas à motivação básica do pesquisador na escolha do tema de pesquisa são decisivas, já que a percepção de que existe uma incompatibilidade entre os interesses da pesquisa básica e os da pesquisa aplicada dá origem a uma fragmentação no interior da comunidade de cientistas que enfraquece sua participação nas arenas de negociação das políticas científicas.

Tradicionalmente, esse tema foi abordado a partir da perspectiva proposta por Vannevar Bush (1990), segundo o qual há uma clara polarização entre esses dois termos: a preocupação com as alternativas de aplicação do conhecimento não é apenas distinta mas também oposta 
àquelas relacionadas com o avanço do conhecimento. Para Bush, a pesquisa aplicada invariavelmente elimina do horizonte a pesquisa pura. Quantas vezes os ecos dessa afirmação não estiveram presentes no debate brasileiro? Em certa medida eles também podem ser percebidos no estudo de Maria Amália de Gusmão.

Entretanto, o livro de Donald Stokes, Pasteur's quadrant, publicado no segundo semestre de 1997 pela Brookings Institution, revê essa perspectiva e redefine a questão. Para Stokes, o objeto de pesquisa não se define numa polarização entre uso e conhecimento, mas sim a partir de um espaço bidimensional, onde as considerações sobre o eventual uso do conhecimento se compõem com a busca do seu avanço. Dessa maneira, temos pela frente não um contínuo, mas um espaço onde é possível identificar quatro quadrantes relevantes. No primeiro quadrante estão as pesquisas cujo objeto é escolhido a partir de uma preocupação disciplinar, que desconsidera a questão do eventual uso do conhecimento. Estas seriam características da pesquisa básica pura, tais como as realizadas, por exemplo, por Bohr. No segundo quadrante estão as pesquisas cujo objeto é produto de uma preocupação com o avanço de questões centrais e, simultaneamente, com as possibilidades de aplicação do conhecimento. Essas são as características, por exemplo, de toda a produção científica de Pasteur nos seus anos de maturidade. Nas pesquisas do terceiro quadrante inexiste preocupação com o avanço do conhecimento; a escolha do objeto é definida apenas pela questão aplicabilidade de seus resultados. Essa é a pesquisa aplicada pura. Finalmente, no ultimo quadrante, a definição do objeto desconsidera ambas as preocupações. São pesquisas que exploram sistematicamente um problema particular, não tendo em vista a generalização ou o uso do conhecimento. Pesquisas desse tipo são muitas vezes utilizadas em situações de sala de aula e são freqüentes em revistas de divulgação.

Como vemos, boa parte das áreas de ponta do desenvolvimento científico contemporâneo ciências da informação, biotecnologias e novos materiais se enquadra na definição de pesquisa "básica-aplicada" proposta por Stokes o quadrante de Pasteur. De fato, como assinala
Ferné, um dos traços centrais dessas novas áreas do conhecimento é o fato de que elas definem seus objetos de pesquisa em função da solução de problemas que se colocam fora dos limites das disciplinas científicas e em contextos de aplicação.

Essa breve caracterização das mudanças recentes no cenário da Ciência e da Tecnologia na virada do século não ficaria completa sem uma referência aos novos circuitos por onde transita parte do conhecimento produzido. Ferné chama a atenção para o fato de que, nas condições em que se dá a produção de conhecimento nas sociedades pósindustriais, uma porção considerável desse conhecimento, especialmente nas áreas mais estratégicas, tende a circular em redes de acesso restrito. Um dos fatores explicativos desse fenômeno é o caráter "proprietário" de parte do conhecimento gerado em redes de cooperação que incluem cientistas industriais e acadêmicos e que é protegido por leis de propriedade intelectual ampliadas. Essa realidade explica e alimenta o desenvolvimento de esquemas de cooperação entre indústrias competidoras e também o apoio da indústria à pesquisa acadêmica. Segundo Ferné, o interesse da área empresarial nos arranjos de cooperação entre universidade e indústria não é ditado apenas pelo interesse nos resultados das pesquisas, mas também pelas possibilidades de constituição de canais de acesso ao conhecimento relevante que circula nessas redes mais restritas.

Cooperação e internacionalização são, portanto, forças motoras do desenvolvimento científico e tecnológico nesse final de milênio. Nunca foi mais evidente o desperdício implícito na perspectiva da "reinvenção da roda" tecnológica, que é básica para o nacionalismo nas políticas de C\&T. Nenhum país, por mais rico que seja, é capaz de arcar com os custos do isolamento. Não obstante, a questão da internacionalização da atividade científica realizada no Brasil tem sido alvo de pouca preocupação por parte das instâncias de planejamento ou de quaisquer dos atores envolvidos nesse debate.

Todavia, a questão é urgente e em outros países tem sido tratada como prioritária. O Plano Nacional de C\&T 
adotado pelo Japão em 1996, por exemplo, contém uma seção inteiramente dedicada a medidas voltadas para reforçar a internacionalização da produção científica japonesa. No outro lado do mundo, no início desse ano, o governo italiano passou a exigir que os projetos de pesquisa que buscam suporte financeiro sejam apresentados simultaneamente em inglês e italiano. O objetivo imediato dessa medida é ampliar a participação de consultores internacionais na avaliação desses projetos, mas, com certeza, ela não deixará de representar um poderoso impulso à internacionalização da pesquisa naquele país.

A temática da internacionalização ficou a descoberto na coletânea que estamos analisando. Outros temas também ficaram de fora. Por outro lado, é mister observar que muitos artigos se sobrepõem e muitas vezes um mesmo tema é abordado por mais de um autor, sem que se note contrastes de opinião marcantes. Muito provavelmente isso decorre do fato de que o livro não é fruto de uma atividade coletiva única um simpósio, um seminário etc. Ao contrário, ele reúne, num formato caleidoscópico, extratos da participação individual de alguns professores e alunos do Programa de Doutorado do Departamento de Sociologia da UnB na vida acadêmica brasileira. Se, de um lado, esse fato tende a dar um caráter fragmentário à obra, de outro, ele empresta a ela o valor de ser uma amostra viva da atividade acadêmica daquele Departamento.

\section{BIBLIOGRAFIA}

BUSH, Vannevar. (1990), Science: the endless frontier. Washington, DC, National Academy of Science Press [1a ed. 1945].

FERNÉ, Georges. (1995), "Science \& Technology in the new world order", in Simon Schwartzman (org.), Science and Technology in Brazil: a new order for a global world, Rio de Janeiro, FGV, pp. 72-104.

GIBBONS, Michael, LIMOGE, Camille, NOWOTNY, Helga, SCHWARTZMAN, Simon, SCOTT, Peter e TROW, Martin.(1994), The new production of knowledge: the dynamics of science and research in contemporary societies. Londres, Sage.

NATIONAL ACADEMY OF SCIENCE. (1996), Reshaping the graduate education of scientists and engineers. Washington, DC, National Academy of Science Press.

STOKES, Donald. (1997), Pasteur's quadrant: basic science and technological innovation. Washington, DC, Brookings Institution Press.

\section{ELIZABETH BALBACHEVSKY}

é professora do Departamento de Ciência Política da Universidade de São Paulo (USP) e pesquisadora associada do Núcleo de Pesquisas sobre Ensino Supeiror (NUPES) e do Núcleo de Pesquisas em Relações Internacionais (NUPRI) da mesma universidade. 